\title{
KEY WORDS ANALYSIS AS IDENTIFIER OF IMPLEMENTATION OF THE EUROPEAN LANDSCAPE CONVENTIONINTO THE STRATEGIC DOCUMENTS OF REGIONS, TOWNS AND RURAL SETTLEMENTS
}

\author{
DUŠAN ŠEBO, MIKULÁŠ HUBA \\ Institute of Geography, Slovak Academy of Sciences, Štefánikova 49, 81473 Bratislava, Slovak Republic; \\ e-mail: geogsebo@savba.sk,geoghuba@savba.sk
}

\begin{abstract}
Šebo D., Huba M.: Key words analysis as identifier of implementation of the European Landscape Convention into the strategic documents of regions, towns and rural settlements. Ekológia (Bratislava), Vol. 32, No. 1, p. 54-65, 2013.

The implementation process of the European Landscape Convention (ELC) still does not receive sufficient academic attention. Its reflection in Slovak Republic municipal strategic documents has especially been neglected. This article presents a simple but appropriate method of rectifying this inadequacy. An analysis of ELC key words occurrence resulting from screening three urban and three rural municipal strategic documents from a region with important cultural-landscape features is presented. A comparison of the results with actual landscape changes is also introduced.
\end{abstract}

Key words: screening, implementation, cluster, cultural landscape changes, European Landscape Convention.

\section{Introduction}

The Slovak Republic as a signatory and party to the European Landscape Convention (ELC) as of 1st December 2005 is obliged to comply with the terms and binding recommendations of this Convention.

The international Vital Landscapes Project and that of the Selected Geographical Aspects of the Environment of Slovakia and its Regions in the International Context supported by the VEGA Grant Agency and others are involved in this compliance with the implementation process of the ELC in the preparation and fulfilment of the aims set by the strategic development documents of the individual municipalities in the territory in question (adapted from; commitments of parties to the ELC; Chapter II, Article 5d):

"Each party undertakes to integrate landscape into its regional and town planning policies and its cultural, environmental, agricultural, social and economic policies, as well as in any other policies with possible direct or indirect impact on landscape."

Strategic development documents should therefore be tools for implementing reaching the landscape quality objectives defined by the ELC as : “...the formulation by the competent public authorities of the aspirations of the public with regard to the landscape features of their surroundings." 
Since not all signed international conventions are followed by their fulfilment, the authors have created a tool here which offers at least partial supervision of how commitments are or are not fulfilled. Consequently, the precise aim of this article is to present a survey of fulfilment of commitments laid down in the ELC, and their inclusion in the strategic development documents of towns and villages. A study with similar aims but a different approach was carried out by Martiš et al. (2006) in the Czech Republic. It is assumed that such reflections and the following assessment, together with systemic updating, will contribute to increased efficiency in implementation commitments laid down by the ELC. Settlements in the Sub-Carpathian Region present an ideal example for the application of this procedure, because:

1. They are located in very valuable landscape - the Central European vine growing landscape.

2. The traditional Sub-Carpathian grape growing landscape is currently under extreme pressure from development and construction companies, because amongst other attractions, it has easy and commuter-friendly accessibility to the Slovak capital city Bratislava. Application of this procedure should lead to increased protection of landscape assets in this territory through strategic municipal documents which contain established strategic objectives and a framework for sustainable development. These documents include those involved in the territorial planning and social and economic development of the studied towns and villages.

Two approaches were applied to assess these documents:

A. Standard: a qualitative content analysis of the strategic development documents and harmony/disharmony of their subject matter with the visions and objectives of the ELC and the aims of the Vital Landscapes Project (for more see Huba, Šebo, 2011).

B. Non-standard: the frequency analysis of key words occurrence.

Since the key words frequency analysis (KW analysis) of printed materials is too laborious, only those municipalities in the model territory which possessed up-to-date electronic versions of the required documents were selected. These municipalities were: Pezinok, Modra, Svätý Jur, Šenkvice, Častá, and Píla.

For the complete survey process, in addition to observation of how the ELC and its objectives are captured in the documents involved, it is also important to check whether the visions and objectives of the ELC contained in the documents are actually implemented. However, this latter issue of assessing the precise changes in landscape and confrontation of the wording of the developmental documents with ELC objectives is not directly treated. Instead, possible links between the analysis of the key words frequency and landscape change assessment is sought. The potential contribution of these two approaches is also assessed.

\section{Material and methods}

Although the objective of KW analysis was not a series of assertions for building a coherent theory but a quantitative expression of certain ELC aspects in individual documents, it was decided to base the approach on content analysis.

Content analysis is the process of grouping and categorizing qualitative text data into clusters of similar content in order to identify certain patterns and relationships between the variables or themes (adapted from Julien, 2008). Data categories studied by content analysis can represent either discrete instances where something does or does 
not occur, or alternatively, the extent to which the studied attribute occurs. It must be added that if the individual categories are assigned word denotations, it is appropriate to use language consistent with the one in the analyzed text. Qualitative or quantitative approaches can be applied in content analysis. The nature of the qualitative approach is deductive. Its principle relies on a thorough reading of the text in an effort to disclose the less evident contextual content. In contrast, the quantitative approach applies induction based on the frequency of selected categories or values connected with certain variables. These two approaches can be combined, depending on the significance of the analysis for the research (Julien, 2008). Content analysis is used for analysis of texts such as transcriptions of interviews, journals or documents, rather than for findings, or field observation notes (Patton, 2002). Using content analysis, Webb et al. (2008) investigated Australian news media discourse concerning how the value orientation in forest management changed over a certain period of time. According to Berg (2000), the content analysis of a written text can be used for the assessment of the following seven principal elements: words or terms, themes, symbols, paragraphs, definitions, concepts and meanings. Antrop (2001), for example, used content analyses to compare concepts and theories from a similar area of interest - landscape ecology and spatial planning. This type of study can contribute to the mutual understanding of experts with different conceptual backgrounds. Words are the basic units used in content analysis. Analyzing words as such normally yields the frequency of specific words or terms. This procedure was selected for our study precisely because it was deemed to be the most appropriate method. It is assumed that the quantitative assessment of the frequency of words occurring with a certain meaning, or those representing a certain aspect of the ELC, should reveal to what extent this aspect is reflected in a given document. To enable precise capture of the given intention of the ELC, the individual aspects were not monitored by means of a single word but each aspect was represented by two or more words. These words were grouped in a total of 14 clusters (Table 1). This grouping was preceded by initial search and combinations of adequate words and the detection of their frequency in different forms, conjunctions and contexts (including synonyms). The intention was to create a workable number of clusters and words representing individual aspects of the ELC. It is important for the observer to be able to memorize all words and to be aware of the cluster to which the sought word belongs. However, the number of words must be sufficient to represent the traced characteristics. Consequently, a reduction in words was made to meet all these requirements. Different specialized software is available to assess word frequency (see. Park, 2012) but our choice was text editor (Microsoft Word) and a PDF document reader (Adobe Reader). Only the stem of the word was entered, and its modifications were sought.

The following criteria had to be applied to obtain the most accurate results possible:

- being particular about the context and not including vague words or duplicates,

- ensuring that the given word was not replaced by a word different to that in the document,

- some words cannot be included in a particular cluster with complete certainty. These either comply with the criteria of several clusters or they gain a contextual meaning which differs to that pursued by the given cluster. The assessor must then make an appropriate decision regarding inclusion of these words,

- words cited in acts, standards and directives such as the names of commissions, branches, and the like, are not included. But the words in the names of maps, figures and tables are included,

- where tables are involved; while words summing up the text are excluded, words in the table which widen the content and meaning of the text are included,

- to prevent duplication, words already included are marked in colour.

There could be an objection that the documents developed and issued before $1^{\text {st }}$ December 2005 on the signing of the ELC by the Slovak Republic cannot be relevantly compared to those processed later. Nevertheless, authors of strategic documentation after $1^{\text {st }}$ December 2005 may not have been familiar with the ELC. The ELC is used here as a reference document. This means that rather than assessing whether the ELC was explicitly mentioned or directly reflected in the studied documents, the intentions intimated in this convention have been estimated here.

In the introduction to this article, the potential significance of a possible link between key word analysis and the assessment of changes in functional land use was mentioned. Since a principal aim of our study is to introduce a possible approach to the assessment of strategic documents (in this case in terms of how they reflect the ELC), assessment of landscape changes will be considered to a lesser extent. For that purpose statistical data providing the basic information on changes in land use in the concerned municipalities were used based on the coefficient of ecological stability, after Míchal (1992). For more details see, for instance, Reháčková, Pauditšová (2007). However, our approach here was modified, placing more emphasis on changes in functional land use than on the assessment of ecological stability and its current status. To this end, a ratio of the forest areas, permanent grassland, public greenery, orchards and vineyards $(\mathrm{N})$ as a numerator and built-up areas $(\mathrm{H})$ as a denominator was formulated. Arable 
$\mathrm{T}$ a b le 1. List of key words (grouped in clusters) representing the main issues of European Landscape Convention.

\section{Sustainable development}

Sustainable development, sustainability

\section{Landscape planning}

Landscape or landscape-ecological planning, territorial system of ecological stability, proposed measures, landscape management, landscape architecture, landscaping, landscape quality objective

\section{Land management}

Land use, maintenance, utilization

\section{Living environment}

Environment, nature conservation, ecological stability

\section{Revitalization}

Preservation, conservation, restoration, improvement, revitalization, humanization of surroundings

\section{Rareness}

Uniqueness, incomparableness, rareness, individuality, richness, irreplaceableness

\section{Heritage}

Heritage (cultural, artistic, industrial), tradition

\section{History}

Value - cultural-historical, aesthetical, cognitive and other nonmaterial landscape value; alleys, parks, orchards (in cultural-historical meaning)

\section{Harmony}

Landscape entity/whole, surrounding, harmony, coherence, context, complex, continuity

\section{Genius loci}

Scenery, panorama, shape, structure, sign, feature, character, impression, appearance, picture, identity, dominants (cultural-historical), visual quality, attractiveness

\section{Stress factors}

Disruption, disturbance, degradation, devastation

\section{Built-up}

Suburbanization, construction (in the context of coordination, regulation etc.)

\section{Landscape synthesis}

Analysis, diagnosis, synthesis, prognosis, potential, strategy, vision

\section{Public}

Communication, perception, participation, opinions

land which represents a relatively unstable area in the original formula was omitted, because this can also appear as a positive variable influenced by factors including the relative size of individual fields, the situation within the cadastral territory and the crops grown. After the mentioned adjustment, the following formula for the computation of the Functional Land Use Index $\left(\mathrm{I}_{\mathrm{flu}}\right)$ was obtained;

$\left(\mathrm{I}_{\mathrm{flu}}\right)=\mathrm{N} / \mathrm{H}$. where; $\mathrm{N}$ and $\mathrm{H}$ stand for the variables mentioned directly above.

The resulting index value was compared at two time horizons (2004 and 2009) - a period during which the intentions of the strategic documentation in force should have become manifest in landscape. To obtain the figure expressing the change in functional land use for a certain period, instead of assessing $\mathrm{I}_{\mathrm{flu}}$ for individual years, this was established as the difference in $\mathrm{I}_{\mathrm{flu}}$ values between 2004 and 2009. This approach makes the comparison of the change of index between individual municipalities for a certain period more objective. Since this is a relatively short period, the aim was not to assess the ecological stability itself or the change in the ecological quality of functional areas falling into the same category during that period (see Lipský, 2000). Since landscaping rather than the eco-stabilizing contribution is assessed here, vine growing areas, for example, are on the same qualitative level as forest areas. The nature of the quoted index is then purely indicative, and in its present form it cannot render a precise summation of detailed changes in functional land use. It should be added that the statistical data do not consider aspects such as the above-mentioned ecological quality of each monitored class, the inherent structure, the importance of the neighbourhood individual classes occupy and the symmetry and harmony of their surroundings. There are also the additional aspects monitored through key word analysis including the level of public participation in the decision-making process, conservation of heritage, revitalization of space and individual perception of landscape changes. If the aim is to asses the actual manifestations of these remaining aspects, the present statistics certainly do not suffice, and it is necessary to implement complex multidisciplinary research. 


\section{Results}

Results of the key word analysis were classified by types of settlements and classes of studied documents. The following $\mathrm{A}-\mathrm{F}$ categories were obtained:

\section{A. Key word analysis of territorial plans for the towns}

Essentials of procuring and processing territorial-planning documentation (TPD) in the Slovak Republic is ruled by $\$ 19$ of Act No. 50/1976 and in the wording of later-issued regulations. In pursuance of this Act, procurement of TPD also includes preparation of surveys and analyses: "Surveys and analysis for the territorial plans both of a region or a municipality prepare an optimal spatial arrangement and functional use of the territory taking into account the landscape-ecological, cultural, historic and socio-economic conditions (hereafter only "landscape-ecological plan")". Consequently, the initial stage of TPD preparation does not necessarily have to deal with the people concerned and their opinion because these should have been sufficiently secured in the previous marking-up process. This is the principal reason why the cluster Public is scarcely represented in TPDs (Fig. 1). However, the lack of attention paid to the terms related to sustainable development is much more alarming. Although these can be replaced by other synonyms and more appropriate terms, the absolute absence of such terms in the TPD of such a valuable but also vulnerable settlement such as Svätý Jur is a bad sign. The clusters of Uniqueness and Heritage, best addressed by Pezinok TPD, should also deserve more attention. For Svätý Jur, however, this absence is partly compensated by the increased frequency of words appurtenant to the Genius loci cluster. Relatively strong representation is evident in the Environment cluster, especially in Pezinok and Modra TPDs, and Modra TPD most frequently uses words in the Revitalisation cluster.

\section{B. Key word analysis of the territorial plans for rural municipalities}

Results for this group reveal that the majority of clusters boast greater representation compared to towns (Fig. 2). One possible explanation for this phenomenon is that towns' development documents concentrate most on the intra-municipal area, while villages in the municipal area also include territories outside their built-up areas but closely connected with local life. This is most obvious in the Landscape Planning and Land Management clusters. While the representation of individual clusters in village TPDs is more or less equal, the Revitalization and Built-up clusters don't follow this pattern and these occur more frequently in the Píla TPD. A positive finding is that village documents mention more words connected with the Environment than towns do, and every village mentions the term Sustainable Development.

\section{Key word analysis applied to programmes for the social and economic development of towns}

Essentials of the Programme of Economic and Social Development (PESD) are briefly defined by Act No. 503/2001 and wording of later issued regulations. This is a medium-period programme document, and in pursance of $\$ 10$ of the above-mentioned Act it should contain 


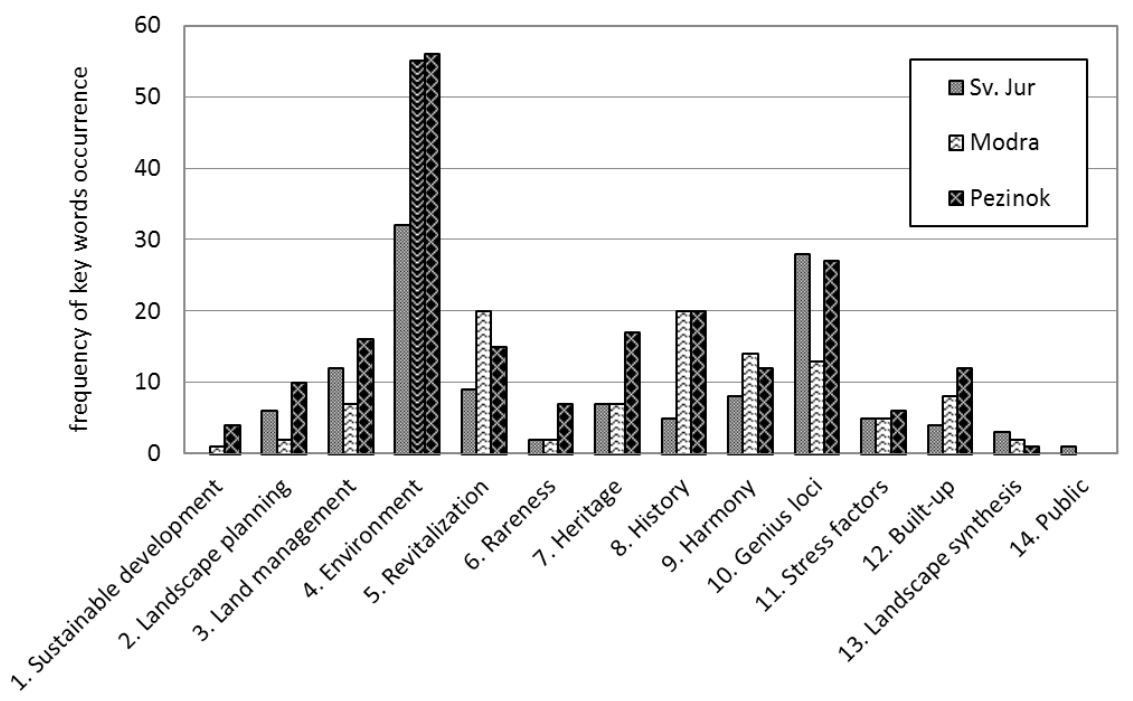

Fig. 1. Key words analysis of Territorial plans in selected towns.

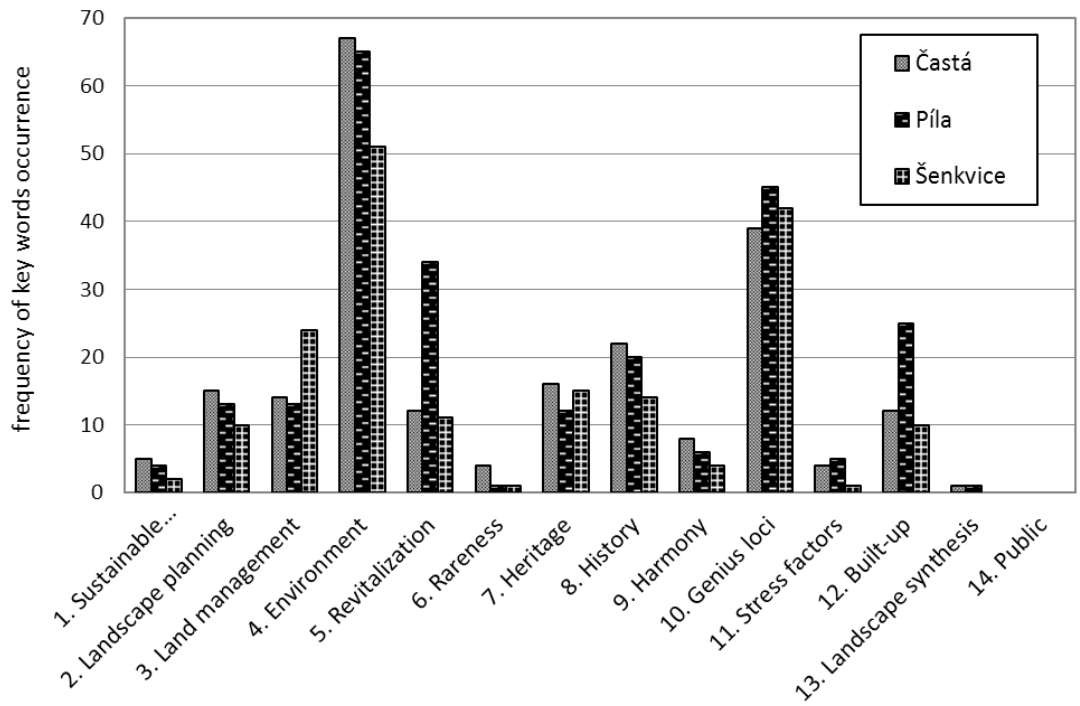

Fig. 2. Key words analysis of Territorial plans in selected villages.

analysis of environmental and cultural development in municipalities. It should also include tasks and basic needs in terms of technological infrastructure and environment, and analysis of social and economic development. The nature of these documents varies depending on the prescribed needs of municipalities and also on the processor. Preparation of this programme document is the responsibility of the authority at the municipality level; here, it is the Mini- 
stry of Construction and Regional Development SR, 2004. Key word analysis of the PESD of towns varies considerably in its individual clusters (Fig. 3). The most conspicuous difference is in the Environment cluster, especially in Svätý Jur and Pezinok documents. While the PESD of Svätý Jur does not even mention sustainable development, this cluster is better addressed in both Modra and Pezinok PESD's than in their TPDs. An important difference from the TPD is the level of attention devoted to the Public cluster, and this is explained by the nature of the document. It is clearly evident that these three towns devote a comparatively large space to this area in their PESD. Representation of the History and Heritage clusters is also interesting because of the different stress laid on them by Svätý Jur on the one hand and by Modra and Pezinok on the other.

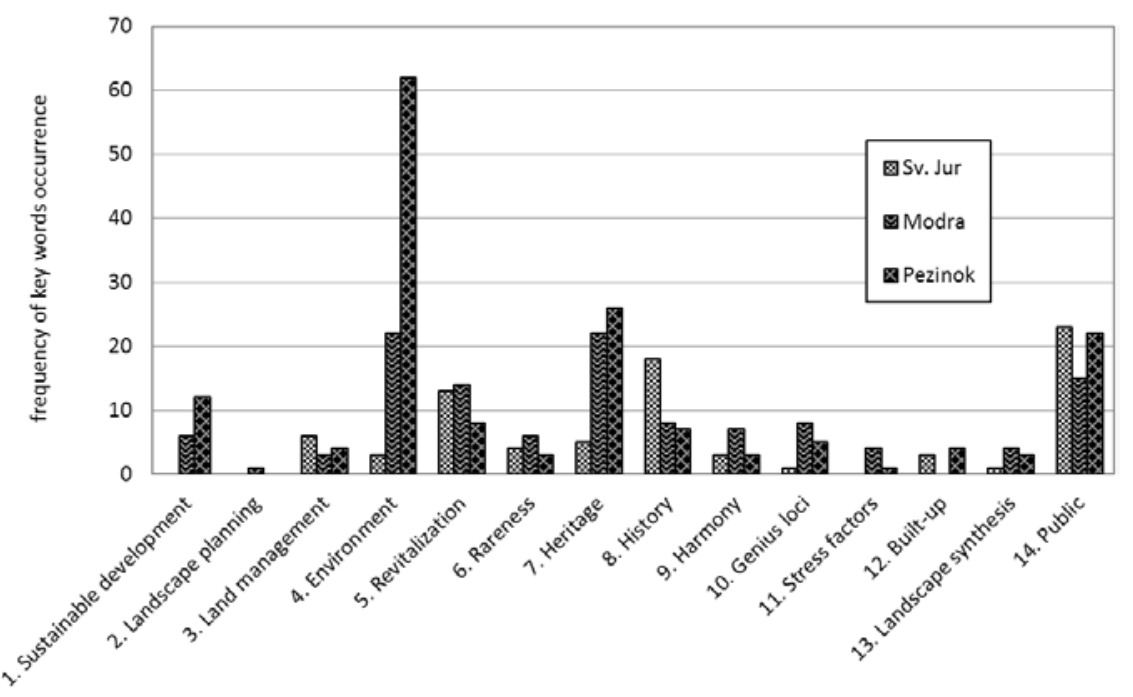

Fig. 3. Key words analysis of Programmes of economic and social development in selected towns.

D. Key word analysis of programmes for the economic and social development of rural municipalities

Results of the key word analysis of the PESD for rural municipalities show a balanced representation of individual clusters for Častá and Píla (Fig. 4.). This is attributed to the fact that these villages are members of the Micro-region Červený Kameň and the two documents are based on this micro-region's PESD. The majority of clusters are more abundantly represented in these documents. In contradistinction, Šenkvice for example does not mention sustainable development in its PESD document and does not deal with terms in the History and Harmony clusters. 


\section{E. Average results of key word analysis of territorial plans of towns and villages}

The chart comparing representation of clusters in towns and villages provides an interesting picture, where villages generally perform better (Fig. 5) There are two possible explanations for this: One is the more frequent use of words represented in individual clusters in village

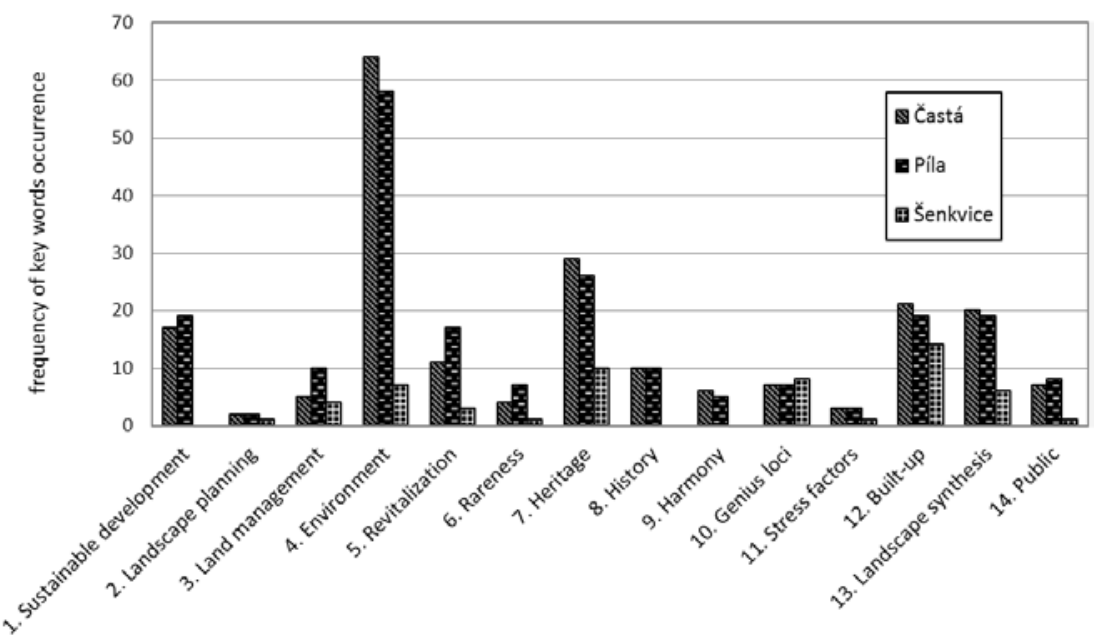

Fig. 4. Key words analysis of Programmes of economic and social development in selected villages.

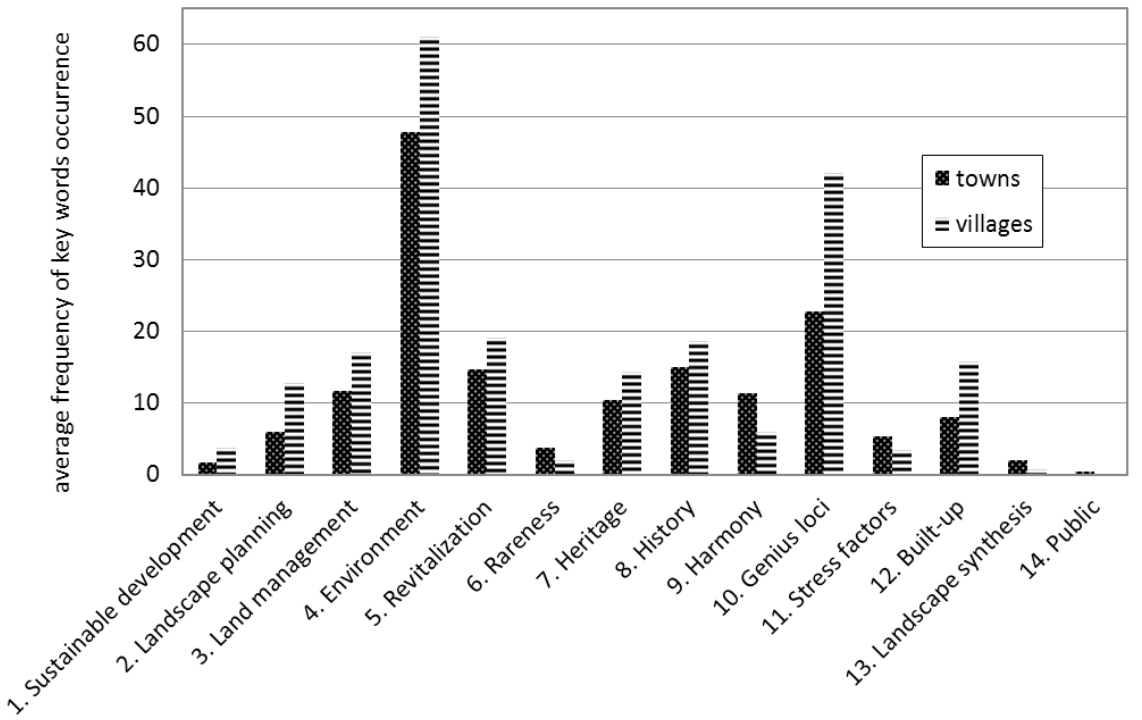

Fig. 5. Key words analysis of Territorial plans in selected settlements. 
areas, and the second is that landscape is very important in rural areas and therefore more relevant in village agendas. If the second explanation is presumed to be the most appropriate one, then the question arises why the Built-up cluster is so poorly represented in town documents compared to village ones, because it may appear logical for towns to devote more attention to construction than rural settlements do.

\section{F. Average results of key word analysis of the PESD prepared for towns and villages}

Similar to the TPD, key words connected with landscape are also more frequent in the PESD of villages than in those of towns, although approaches of individual villages differ considerably. The only distinctly represented cluster in town documents is Public. Article $5 \mathrm{c}$ of the European Landscape Convention binds all relevant entities to secure public participation in defining and instituting landscape concepts which the assessed documents definitely represent. Public participation, not only in the marking-up process but also in preparation of landscape concepts in their initial stages, is the indispensable condition of their correct formulation and consequent observation.

\section{Index of functional land use}

As we already suggested, identifying the extent to which the strategic documents deal with the European Landscape Convention is only one part of the implementation process. The second part should yield information about resultant manifestations of aims and priorities of the strategic documents for the landscape. Statistical data on land use in the individual municipalities was used to describe how this part of the process should be carried out. Apart from the above-mentioned problems, there is another drawback in working with statistical data - that of inaccurate recordings, particularly those involved with changes in land use. In one case, the extent of built-up areas was reported as decreasing by more than 5 ha between 2004 and 2009 when the reality was most likely an increase. In addition to depicting the above example, Table 2 highlights the more pronounced statistically recorded decrease in Častá village. Although similar anomalies are most likely caused by altered classification in functional land use, the records still prove unreliable for assessment of actual landscape changes because verification by aerial imaging or surveys is lacking.

As evident from changes in the functional land use index in Table 2 and Figure 7 such calculation provides a clear idea how landscape (in this case land use) changes over time. If these results were used as the basis, it would be evident that the most favourable changes took

T a b le 2. Land use statistical data $\left(\mathrm{m}^{2}\right)$ and Functional land use index $\left(\mathrm{I}_{\text {flu }}\right)$.

\begin{tabular}{|c|c|c|c|c|c|c|c|c|c|c|c|c|c|c|c|}
\hline \multirow{2}{*}{ Municipality } & \multicolumn{2}{|c|}{ Built-up area } & \multicolumn{2}{|c|}{ Public greenness } & \multicolumn{2}{|c|}{ Vineyards } & \multicolumn{2}{|c|}{ Orchards } & \multicolumn{2}{|c|}{ Grass plots } & \multicolumn{2}{|c|}{ Forest } & \multicolumn{2}{|l|}{ Ifiu } & \multirow{2}{*}{\begin{tabular}{|c|} 
Change of $I_{\text {flu }}$ \\
$2009-2004$ \\
\end{tabular}} \\
\hline & 2004 & 2009 & \begin{tabular}{|l|}
2004 \\
\end{tabular} & 2009 & 2004 & \begin{tabular}{|l}
2009 \\
\end{tabular} & 2004 & 2009 & 2004 & 2009 & 2004 & 2009 & 2004 & 2009 & \\
\hline Modra & 3282693 & 3228904 & 215000 & 215000 & 7887268 & 7411643 & 123338 & 85424 & \begin{tabular}{|l|}
3744777 \\
\end{tabular} & \begin{tabular}{|l|}
3973396 \\
\end{tabular} & 23718274 & 23698649 & 10.87 & 10.96 & 0,09 \\
\hline Pezinok & 6211639 & 6569012 & 312200 & 350500 & 9051072 & 8997139 & 26774 & 26774 & \begin{tabular}{|l|}
3236329 \\
\end{tabular} & 2696422 & 39459306 & 39449878 & 8.39 & 7.84 & -0.54 \\
\hline Svätý Jur & 1443925 & 1542944 & 52900 & 51700 & 4133904 & 3661279 & 13993 & 5418 & 1234672 & 1075210 & 22155294 & 22133366 & 19.11 & 17.45 & -1.66 \\
\hline Towns & 10938257 & 11340860 & 580100 & 617200 & 21072244 & 20070061 & 164105 & 117616 & 8215778 & 7745028 & 85332874 & 85281893 & 10.55 & 10.04 & -0.51 \\
\hline Šenkvice & 1857178 & 1883491 & 29500 & 104800 & 1380584 & 1369258 & 43706 & \begin{tabular}{|r|}
43706 \\
\end{tabular} & 34014 & 33977 & 5411813 & 5305978 & 3.72 & 3.64 & -0.07 \\
\hline Častá & 1063685 & 954385 & 41000 & 41000 & 1920079 & 1923843 & 168499 & 169145 & 639380 & 572427 & 26064572 & 26271612 & 27.11 & 30.36 & 3.26 \\
\hline Píla & 115755 & 120033 & 5000 & 5000 & 0 & 0 & 0 & 0 & 121027 & 117917 & 80874 & 80874 & 1.79 & 1.70 & -0.09 \\
\hline Villages & 3036618 & 2957909 & 75500 & 150800 & 3300663 & 3293101 & 212205 & 212851 & 794421 & 724321 & 31557259 & 31658464 & 11.84 & 12.18 & 0.35 \\
\hline
\end{tabular}




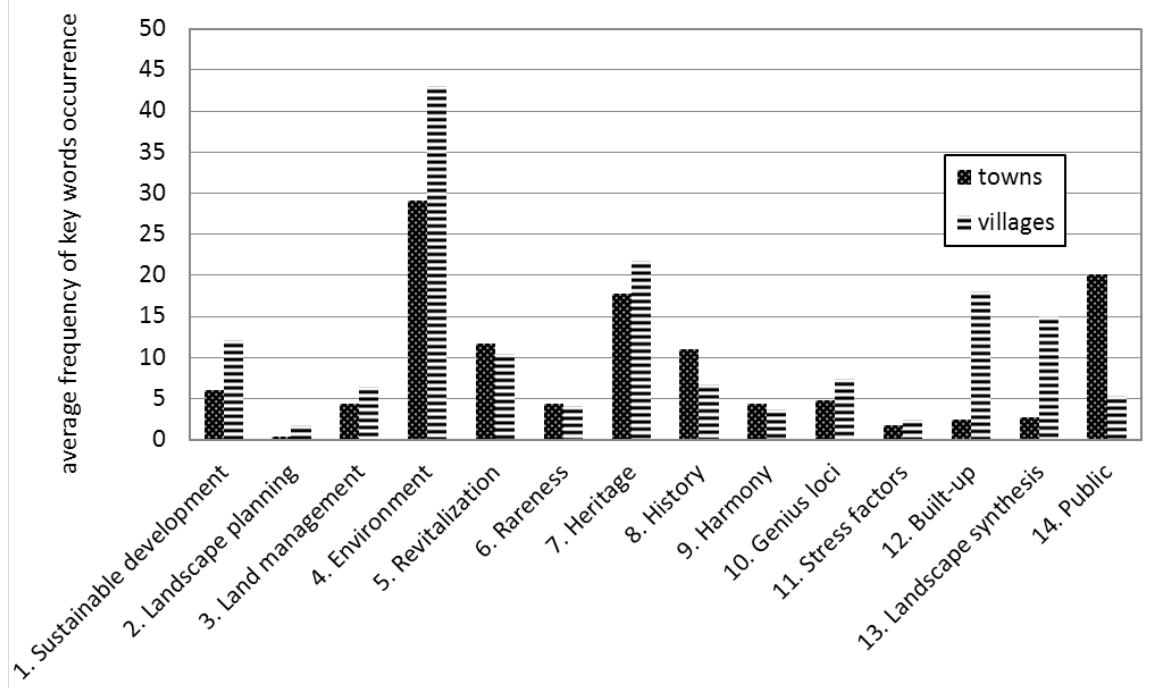

Fig. 6. Key words analysis of Programmes of economic and social development in selected settlements.

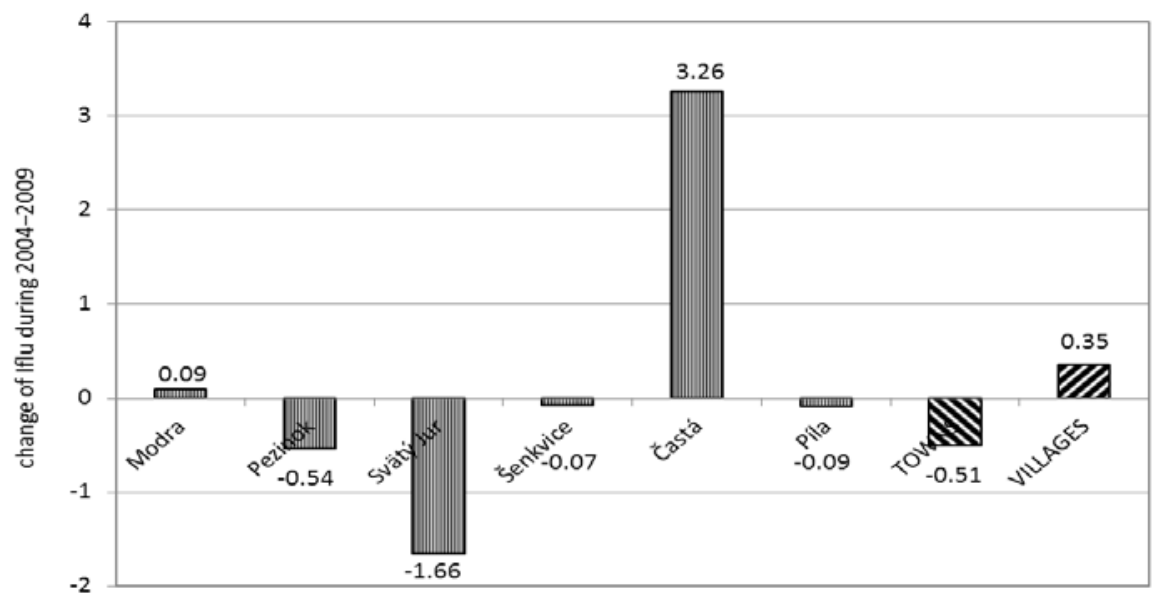

Fig. 7. Change of Landscape functional use index $\left(I_{f l u}\right)$ in selected municipalities during 2004-2009.

place in Modra (towns) and in Častá (villages). Comparison of these data with the key word analysis shows a certain disparity, especially for towns. Judging by the level of attention the strategic documents devote to individual clusters, although comparison of the TPD of the three towns in this region indicated that the most favourable landscape changes should be expected in Pezinok, estimation of $\mathrm{I}_{\mathrm{flu}}$ changes showed Pezinok ending up behind Modra in this respect. When the above-mentioned statistical drawbacks are considered, Pezinok may 
have achieved a relatively better result with regard to the specific features of the content of strategic documents of towns. The interpretation of results is very similar for villages, where although Častá attained better key words analysis results with the best value of differences in $I_{\text {flu' }}$, they are biased by the same statistical drawbacks.

The comparison of results of analyses for both types of settlements is also interesting, because the presumption of biased results caused by statistical drawbacks is quite minor due to the distribution of errors between several towns on the one hand and several villages on the other. This comparison result is more objective than that for individual municipalities. Consequently, key word analysis shows that village strategic documents are more oriented to landscape than town documents (Figs 5,6). If the work agenda of villages followed these documents then the actual manifestations in landscape should correspond to the agenda. Our simplified statistical exploration proved this presumption correct, so the conclusion can be drawn that both towns and villages do by and large implement their strategic documents.

\section{Discussion}

Results of this research suggest that rural settlements in the region concerned possess more pro-landscape conceived strategic documents than towns. The intentions of such documents are also obvious in the landscape. However, it is not possible to arrive at conclusions concerning the precise projection of strategic documents in the landscape from a simple analysis of statistical data. Here, the principal aim was to develop and test a method to establish the scope, rate and quality of implementation of the European Landscape Convention in the strategic documents of towns and villages of the selected region, and to indicate a possible way to verify the identified rate of implementation through actual manifestations in the landscape.

A more detailed analysis of the resultant landscape-ecological, aesthetic, cultural, historical, symbolic and other landscape changes may provide precise information concerning the extent to which individual settlements comply with the landscape agenda of their strategic documents. This is a time-demanding task as the manifestation of landscape changes on a settlement scale may only become evident after more than five years.

\section{Conclusion}

This article presents a method of identifying the rate of implementation of the European Landscape Convention, which should establish the extent to which strategic documents reflect the ELC. Its advantages include the option of comparing the implementation rate of individual municipalities because the assessment results are quantified. However, this approach risks shallowness and inappropriate generalization. These weaknesses were partly counteracted by the approach described in the methodological part of this article and by exact processing of the key word analysis. This article supplements our earlier study where revision of the ELC implementation and principles of sustainability were performed by qualitative analysis (Huba, Šebo, 2011). This methodology failed to eradicate problems ensuing from subjectivity, and the conclusions reached proved too specific. Based on the experience gained in that research, it appears that the qualitative approach in strategic documentation 
assessment is more suitable when one or a few municipalities are involved, and the quantitative approach is more appropriate for larger numbers of municipalities. The combination and subsequent comparison of these two approaches appears optimal.

The appropriateness of this type of revision lies not only in the comparison of documents prepared by municipalities but also in the pressure placed on vagueness in the terms used and on the copying of texts or formalism in documents accompanying applications for grants and funds which otherwise do not reflect the real needs for municipal sustainable development. This approach is often evident in plans for economic and social development, preparation of which is not as strictly prescribed by the law as for territorial plans. Moreover, the existence of the PESD of a municipality is a prerequisite for drawing on EU Structural Funds and some governmental subsidy programmes - often, unfortunately, the only motive for their procurement. The intention of this article is to submit a suitable measure for the prevention of such phenomena.

Translated by H. Contrerasová English corrected by R. Marshall

\section{Acknowledgements}

The article is based on data and information gained thanks to the financial support of the following projects:

"Assessment and Sustainable Development of Cultural Landscape by Application of Innovative Participative and Visualizing Tools" - acronym Vital Landscapes (supported by European Territorial Cooperation Objective, CENTRAL EUROPE Programme No. 2CE164P3) and "Selected geographical aspects of environmental developments in Slovakia and its regions in the international context" (supported by VEGA - Scientific grant agency of the Ministry of Education, Science, Research and Sport of the Slovak Republic and of Slovak Academy of Sciences No.2/0111/12).

\section{References}

Antrop, M. (2001). The language of landscape ecologists and planners. A comparative analysis of concepts used in landscape ecology. Landsc. Urban Plann., 55(3), 163-173. DOI:10.1016/S0169-2046(01)00151-7.

Berg, B.L. (2000). Qualitative research methods for the social sciences. Needham Heights: Ally \& Bacon.

Council of Europe. (2000). European Landscape Convention. Florence: Council of Europe.

Huba, M. \& Šebo D. (2011). Vital Landscape International Project with the participation of the Institute of Geography SAS. In Research and Management of the Historical Agricultural Landscape, 14-16 March (pp. 167-178). Viničné, SK: ILE SAS.

Julien, H. (2008). Content analysis. In The Sage encyclopedia of qualitative research methods. (Vol. 1 \& 2, pp. 120122). Thousand Oaks: The Sage encyclopedia of qualitative research methods.

Lipský, Z. (2000). Observation of changes in cultural landscape (in Czech). Kostelec nad Černými lesy: UAE LF, ČZU.

Martiš, M., Andělová, B. \& Zdražil, V. (2006). The survey of landscape development activities in relation to implementation of the European Landscape Convention in the Czech Republic. Ekológia (Bratislava), 25(Suppl. 3), $180-193$

Míchal, I. (1992). Ecological stability (in Czech). Brno: Veronica.

Ministry of Construction and Regional Development. (2004). Methodical guidelines for elaboration of the Programme of economic and social development. Bratislava, SK: Ministry of Construction and Regional Development.

Park, H.W. (2012). Examining academic Internet use using a combined method. Quality and Quantity, 46(1), 251266. DOI:10.1007/s11135-010-9344-6.

Patton, M.Q. (2002): Qualitative research \& evaluation methods. Thousand Oaks: Sage.

Reháčková, T. \& Pauditšová, E. (2007). The methodology of determining of landscape ecological stability coefficient (in Slovak). Acta Environmentalica Universitatis Comenianae, 15(1), 26-38.

Webb, T.J., Bengston, D.N. \& Fan D.P. (2008). Forest orientations in Australia: an application of computer content analysis. Environ. Manag., 41(1), 52-63. DOI:10.1007/s00267-007-9011-4. 